\title{
Incidental finding of "empty sella" and prevalence of endocrine disturbances - A systematic review
}

M. Stieg ${ }^{1}$, M. Auer ${ }^{1}$, G.K. Stalla ${ }^{1}$, C. Sievers ${ }^{1}$, A. Kopczak ${ }^{1}$

${ }^{1}$ RG Clinical Neuroendocrinology, MPI of Psychiatry, Munich

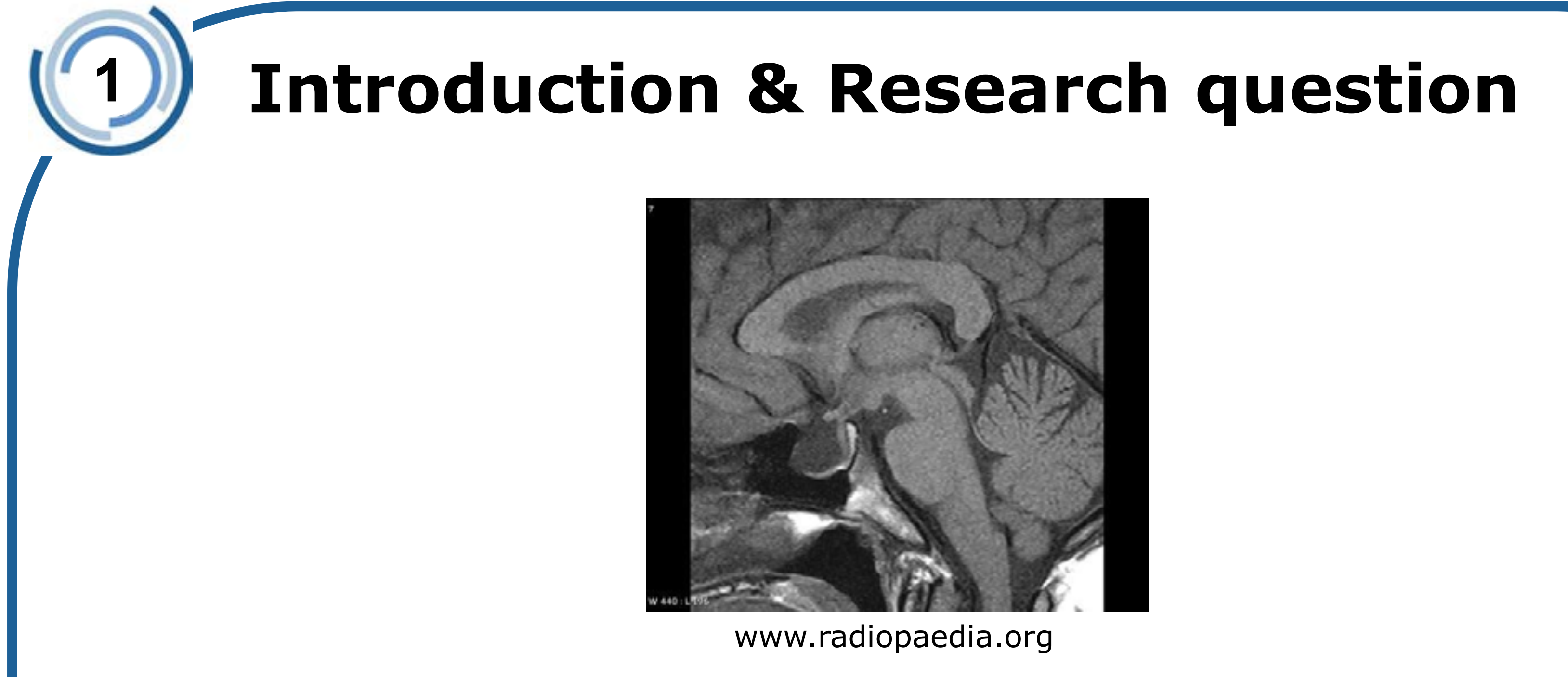

Neuroimaging techniques have improved over the last years

"empty sella" is more often incidentally diagnosed

Is a routine neuroendocrine assessment necessary in patients with primary empty sella syndrome (PES) without clinical suspicion or history of neuroendocrine disorders?
2) Methods: Systematic literature research

1398 studies in PubMed with the search term "empty sella"

606 studies between 1995 and 2015

456 studies excluded, i.a.

- 301 case reports ( $\mathrm{n} \leq 3$ patients)

- 79 pediatric patients $(<18 \mathrm{yrs})$

- 7 studies with exclusion of PES

- 6 animal studies

150 studies with empty sella in adult patients

\section{1 studies with secondary empty sella}

69 full text studies

65 studies excluded, i.a.

- text not available in English

- no endocrine assessment

- no incidental finding

4 studies included

Fig 1. PRISMA four phase flow diagram

(3)

\section{Results}

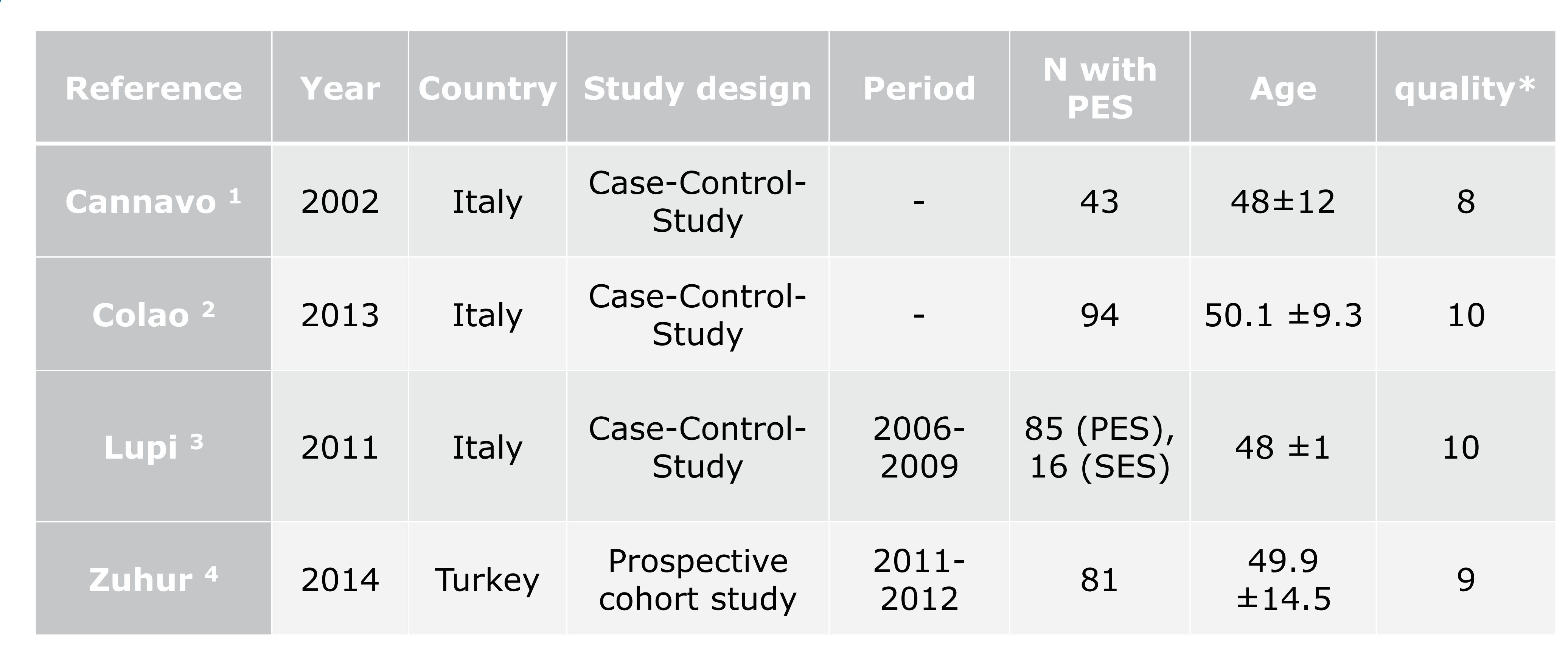

*assessed with the quality appraisal tool ( 0 poor quality -10 high quality)

Fig. 2 Study characteristics

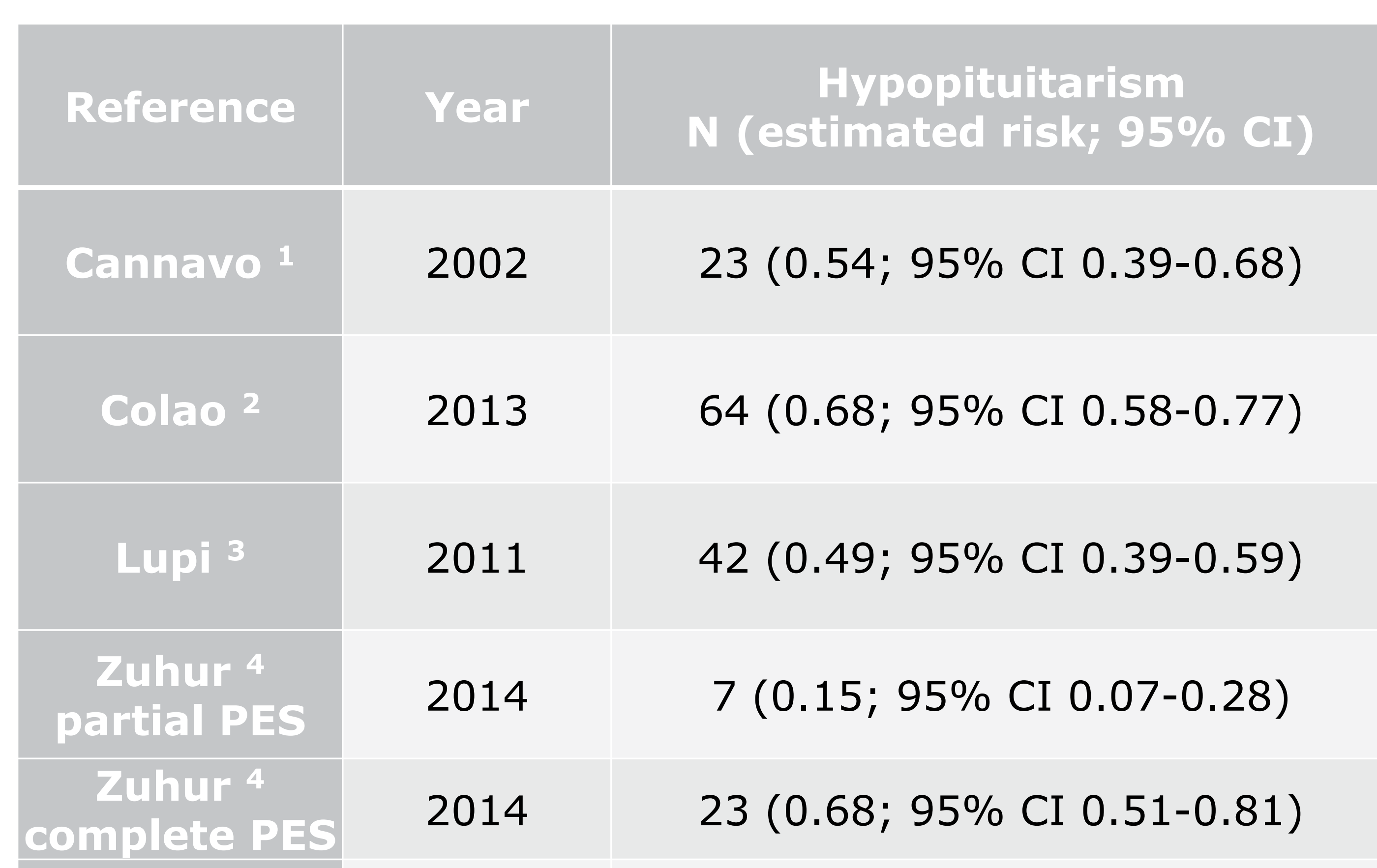

$159(0.50 ; 95 \%$ CI $0.33-0.67)$

Fig. 3 Meta-analysis

$\mathrm{Cl}=$ confidence interval

\section{Discussion \& Recommendation}

- pooled prevalence of hypopituitarism: 50\%

- only 4 studies included in meta-analysis

- somatotropic and gonadotropic axes are most often impaired (data not shown)

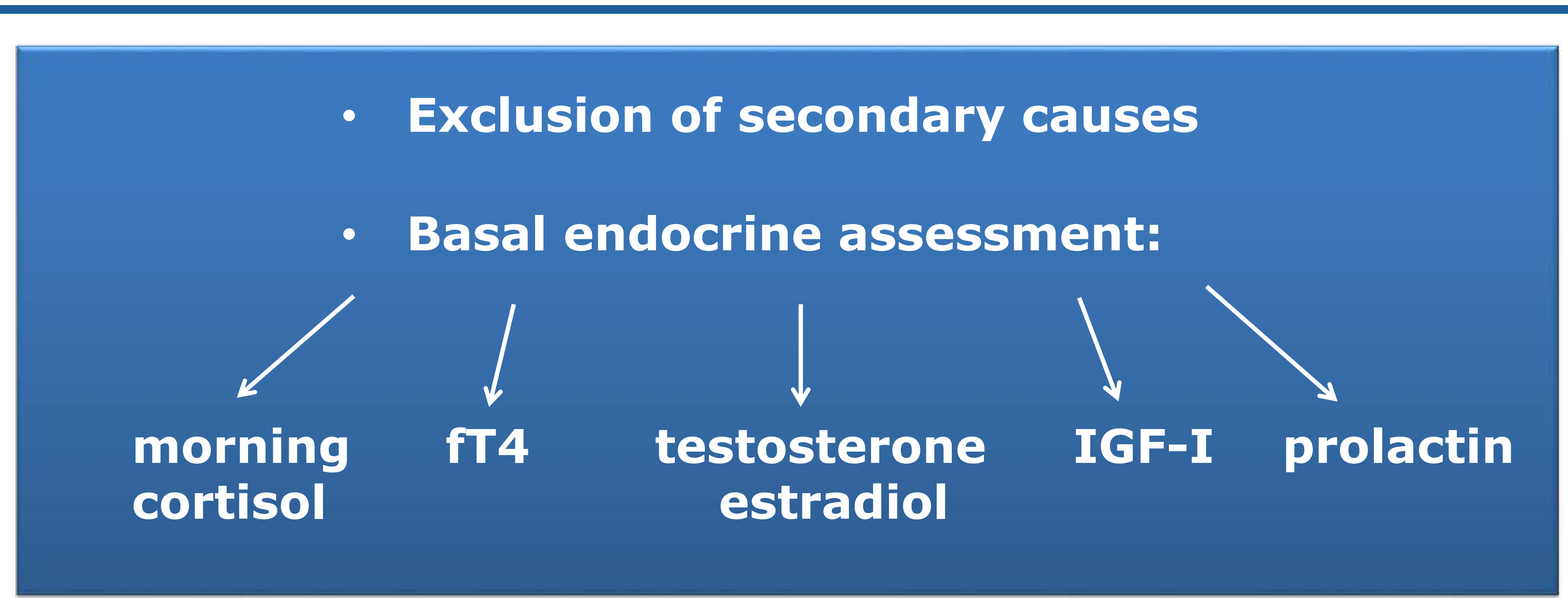

Exclusion of secondary causes

asal endocrine assessment:

testosterone estradiol

\section{References}

Cannavò S, Curtò L, Venturino M, Squadrito S, Almoto B, Narbone MC, Rao R, Trimarchi F. Abnormalities of hypothalamic-pituitary-thyroid axis in patients with primary empty sella. J Endocrinol Invest. 2002 Mar;25(3):236-9. ${ }^{2}$ Colao A, Cotta OR, Ferone D, Torre ML, Ferraù F, Di Somma C, Boschetti M, Teti C, Savanelli MC, Alibrandi A, Trimarchi F, Cannavò S. Role of pituitary dysfunction on cardiovascular risk in primary empty sella patients. Clin Endocrinol (Oxf). 2013 Aug;79(2):211-6.

${ }^{3}$ Lupi I, Manetti L, Raffaelli V, Grasso L, Sardella C, Cosottini M, lannelli A, Gasperi M, Bogazzi F, Caturegli P. Martino E. Pituitary autoimmunity is associated with hypopituitarism in patients with primary empty sella. J Endocrinol Invest. 2011 Sep;34(8):e240-4

Zuhur SS, Kuzu I, Ozturk FY, Uysal E, Altuntas Y. Anterior pituitary hormone deficiency in subjects with total and partial primary empty sella: do all cases need endocrinological evaluation? Turk Neurosurg. 2014:24(3):374-9..

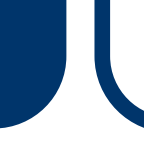

